\title{
Update on the management of infant and toddler developmental dysplasia of the hip
}

Brian Loh, Emily Woollett

This article is the third in a commissioned series on paediatric orthopaedics.

\section{Background}

Developmental dysplasia of the hip (DDH) encompasses the pathological spectrum of hip instability that produces subluxation or dislocation and radiological features of abnormal acetabular development. It is important to approach DDH with sound prior knowledge to recognise, diagnose and manage its variety of presentations.

\section{Objective}

The aim of this article is to summarise contemporary practice in DDH with an emphasis on recent changes in diagnosis, surveillance and treatment recommendations for general practitioners (GPs), who see infants and toddlers in practice.

\section{Discussion}

The management of DDH requires accurate diagnosis of the pathoanatomy and depends on the age of the child. GPs are essential for the early detection of $\mathrm{DDH}$, which then allows for harnessing of the remodelling potential of the hip cartilaginous anlage to achieve a stable and mature hip. GPs also play an important part in surveillance, and this article provides an update on the pivotal points.
THE HUMAN ACETABULUM is shallower at birth than at any other time during development. The embryonic acetabulum begins as a deeply set cavity that almost entirely encloses the femoral head but gradually becomes shallower as birth approaches. This trend reverses after birth, with the acetabulum deepening, femoral head coverage increasing and hip morphology improving. ${ }^{1}$

Teleologically, it is possible that a temporarily increased hip range of motion in the third trimester is required to accommodate the lower limb within the limited intrauterine space. Postnatally, the sphericity of the femoral head and deepening of the acetabulum are expected to increase progressively through childhood. ${ }^{1,2}$

The wide spectrum of pathology affecting this process is named developmental dysplasia of the hip (DDH). Presentations can vary from an infant born with a fixed, irreducible dislocated hip through to mild acetabular dysplasia only diagnosed in adulthood. ${ }^{3}$ Management of this wide continuum of pathology requires careful consideration, because management varies greatly as the age of the child increases. ${ }^{4}$

$\mathrm{DDH}$ and its sequelae continue to have a major impact on healthcare, with the Australian Orthopaedic Association National Joint Replacement Registry (AOANJRR) reporting that nearly $7 \%$ of total hip replacements in Australia are directly attributable to DDH. ${ }^{5}$

The emphasis of this article is on the management of DDH in infancy and the early years; management of DDH during adolescence and adulthood is not included.

\section{Establishing the diagnosis}

As previously stated by Williams, 'repeated, carefully performed clinical examinations of the paediatric hip from newborn to walking age remain the best method for early detection of DDH'. ${ }^{6}$ This, combined with an understanding of the risk factors, will help in the early diagnosis and management of children with DDH (Table 1).

The priority is differentiating between neonatal hip instability, acetabular dysplasia and subluxation or dislocation of the hip, as severity of involvement (Figure 1) determines the treatment required to obtain a concentric reduction.

Neonatal hip instability is laxity limited to the hip joint capsule and is influenced by hormonal and genetic factors. ${ }^{7-10}$ This laxity has a natural tendency to correct itself, with $95.3 \%$ of hips returning to normal morphology by 12 weeks of age. ${ }^{11}$

The spectrum continues to more severe forms of dysplasia with worsening hip instability, to the established hip subluxation with significant hip dysplasia, some of which may then progress to frank hip dislocation. ${ }^{3,4,11,12}$ 


\section{Imaging for DDH}

\section{Ultrasonography}

In the presence of risk factors or with an equivocal clinical examination, ultrasonography is the reference standard in children aged $<6$ months (before the proximal femoral ossific nucleus is visible). ${ }^{13}$

The Graf method subscribes to a table of $\alpha$ and $\beta$ angles to provide a quantitative classification system, ${ }^{2}$ while the dynamic (Harcke) technique for position and stability has qualitative definitions. ${ }^{14}$ New ultrasonography techniques using three-dimensional probes and machine learning have built on existing two-dimensional ultrasonography techniques to produce three-dimensional renderings of the infant hip joint ${ }^{15,16}$ to improve interobserver reliability.

\section{Radiography}

After the age of five months, the femoral epiphyseal ossification centre begins to obscure sonographic landmarks. ${ }^{13,17}$ The pelvic radiograph is the benchmark for surveillance of acetabular development, especially with the introduction of the International Hip Dysplasia Institute
(IHDI) classification method, which demonstrates excellent interexaminer reliability even when ossific nuclei are absent or delayed. ${ }^{18}$

\section{Magnetic resonance imaging}

Magnetic resonance imaging (MRI) has the benefit of being non-invasive and offers a level of anatomic detail that allows for differentiation of ossified and unossified structures. It is an excellent modality in the intra-operative period, usually after reduction and spica casting, to assess the concentricity of reduction. ${ }^{17}$

Hip MRI protocols enable efficient and accurate evaluation of the hip cartilaginous anlage, the ligamentous and soft-tissue abnormalities that may obstruct successful reduction, ${ }^{17}$ without exposure to ionising radiation. Table 2 lists anatomic structures and the respective MRI findings in DDH.

\section{Goals of treatment}

\section{Obtaining a concentric reduction}

A concentric reduction refers to a situation in which the femoral head is well docked in the acetabulum. It is required for the long-term goal of a congruent, spherical hip at skeletal maturity. ${ }^{12,19}$ Reduction of the hip is relatively straightforward in neonatal hip instability, but if the hip subluxates and remains incongruent while braced, soft tissue obstacles to reduction may develop, obstructing concentric reduction of the femoral head into the acetabulum (Figure 2). ${ }^{3,4,17}$

\section{Maintaining reduction and stability of the hip}

Once reduction of the hip has occurred, it is imperative to maintain the reduction until the hip is stable and is developmentally normalising. ${ }^{20}$ There are several contributing factors that affect persistent hip instability, primarily bony deformities in the coronal and transverse planes. Many hips affected by DDH have excessive femoral anteversion, abnormal acetabular version, coxa valga and residual acetabular dysplasia (Figure 3). ${ }^{19,21}$

\section{Stimulating development of normal hip morphology}

Timely DDH treatment uses the hip's ossification potential to obtain a

Table 1. Developmental dysplasia of the hip: Referral guidelines

\begin{tabular}{|c|c|c|}
\hline Initial work-up & $\begin{array}{l}\text { Suggested general } \\
\text { practitioner management }\end{array}$ & $\begin{array}{l}\text { When to refer to paediatric } \\
\text { orthopaedics }\end{array}$ \\
\hline $\begin{array}{l}\text { Clinical history } \\
\text { Risk factors: } \\
\text { - Female sex } \\
\text { - Breech delivery } \\
\text { - Intrauterine packaging deformities } \\
\text { (eg plagiocephaly, foot deformities or torticollis) } \\
\text { - Family history of DDH } \\
\text { Physical examination } \\
\text { - Hip examination to check for instability } \\
\text { with Barlow's and Ortolani's tests } \\
\text { - Limited abduction } \\
\text { - Deep uneven gluteal crease } \\
\text { - Leg length discrepancy } \\
\text { - Waddling gait after walking age } \\
\text { Investigations } \\
\text { - Hip ultrasonography if aged } \leq 6 \text { months } \\
\text { (paediatric ultrasonography service if possible) } \\
\text { - Plain X-ray if aged }>6 \text { months }\end{array}$ & $\begin{array}{l}\text { Screening } \\
\text { - Screening ultrasonography if risk factors } \\
\text { present in child aged }<6 \text { months } \\
\text { - Screening ultrasonography at six weeks of age } \\
\text { for all breech presentation babies } \\
\text { - Plain film X-ray (anteroposterior pelvis with } \\
\text { leg in extended position and 'frog leg' views) } \\
\text { if risk factors present for a child aged } \\
>6 \text { months } \\
\text { Surveillance } \\
\text { - Surveillance anteroposterior pelvis X-ray } \\
\text { at } 12 \text { months of age if child previously } \\
\text { investigated for DDH (because of incidence } \\
\text { of late-presenting DDH) }\end{array}$ & $\begin{array}{l}\text { Urgent } \\
\text { - Abnormal clinical examination } \\
\text { - Positive Barlow's or Ortolani's test } \\
\text { - Limited hip abduction } \\
\text { - Leg length discrepancy } \\
\text { - Abnormal ultrasound or X-ray } \\
\text { - To properly triage the referral, } \\
\text { access to the radiological images } \\
\text { is required to ensure that the } \\
\text { radiological interpretation is correct }\end{array}$ \\
\hline
\end{tabular}


reduced, stable and developmentally appropriate hip while aiming to avoid the complications of growth disturbance and osteonecrosis. ${ }^{22,23}$ Early reduction facilitates normal acetabular development and reduces the need for later pelvic surgery. A concentric reduction normalises the joint forces, which stimulates remodelling and reorientation of the growing hip..$^{4,9,12,24,25}$

\section{Avoiding complications}

Interruptions to proximal femoral growth, and osteonecrosis of the femoral capital epiphysis presumably occur as a result of vascular damage to the proximal femur during hip reduction and stabilisation..$^{20,25,26}$ Care must be taken at each step of treatment to minimise the risk of iatrogenic injury.

\section{Treatment options}

\section{Hip abduction bracing}

In a child aged $<4$ months, an 'abduction brace', commonly the Pavlik harness or Denis Browne hip abduction brace, is used for an unstable hip. ${ }^{23-25}$ The semi-rigid immobilisation of the Denis Browne brace is preferred to the Pavlik harness in the older child who is beginning to roll.

In children with dislocated hips, bracing may be applied but must be closely monitored and re-examined within two

\section{Table 2. Magnetic resonance imaging findings of the anatomic structures involved in developmental dysplasia of the hip}

\begin{tabular}{ll}
\hline Anatomic structures & Imaging findings \\
\hline Acetabular morphology & Shallow, dysmorphic acetabulum with abnormal cartilage anlage \\
\hline Femoral morphology & Delayed ossification of non-spherical femoral head \\
\hline Labrum & Labral hypertrophy (limbus) with mucoid degeneration \\
\hline Pulvinar & Pulvinar hypertrophy with fibrofatty proliferation \\
\hline Ligamentum teres & Hypertrophy with contraction of the transverse acetabular \\
\hline Hip capsule & ligament \\
\hline
\end{tabular}

weeks to confirm concentric reduction both clinically and radiologically. If reduction is not achieved within this timeframe, bracing must be reconsidered and an alternative treatment method chosen. ${ }^{4,23,24}$

Complications of bracing include: failure to obtain and maintain reduction, leading to potential worsening of DDH with posterior acetabular insufficiency and deformation of femoral head cartilage anlage; femoral nerve palsy; inferior dislocation; and osteonecrosis..$^{24,25,27}$ It is important to engage the parents of the child with pretreatment education, ongoing counselling and support during the course of treatment, as hip abduction bracing requires familial compliance to succeed.

\section{Closed reduction, arthrography and spica cast application}

If hip abduction bracing fails, or if the child presents at an older age, then a gentle closed reduction under general anaesthesia with spica cast immobilisation is the next option. An arthrography should be performed concurrently to ensure that the reduction has truly occurred and that there are no intra-articular obstacles that may prevent reduction. ${ }^{28}$ In some patients, an adductor contracture may prevent reduction, and this may be addressed
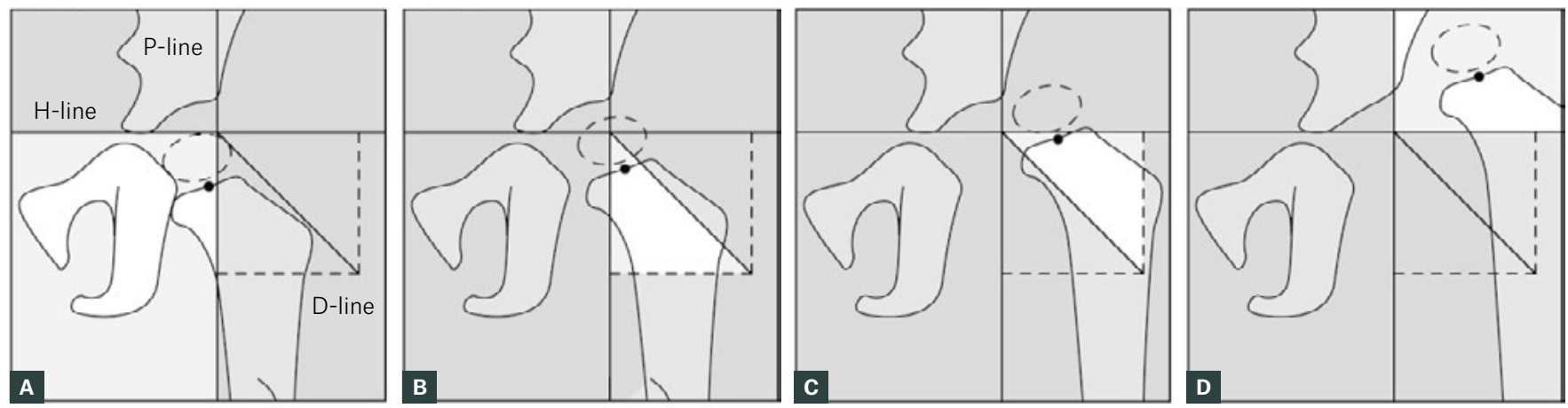

Figure 1. International Hip Dysplasia Institute classification for severity of developmental dysplasia of the hip (not requiring the presence of an ossific nuclei). ${ }^{18} \mathrm{H}$-line is Hilgenreiner's line, drawn through the top of the triradiate cartilages bilaterally. P-line is Perkin's line, drawn perpendicular to the $\mathrm{H}$-line at the superolateral margin of the acetabulum. $\mathrm{D}$-line is the diagonal line drawn $45^{\circ}$ from the junction of $\mathrm{H}$-line and $\mathrm{P}$-line. $\mathrm{H}$-point is the midpoint of the superior margin of the ossified metaphysis.

A. Grade I: the H-point is at or medial to the P-line; B. Grade II: the H-point is lateral to the P-line and at or medial to the D-line; $\mathbf{C}$. Grade III: the $\mathrm{H}$-point is lateral to the D-line and at or inferior to the $\mathrm{H}$-line; D. Grade IV: the $\mathrm{H}$-point is superior to the $\mathrm{H}$-line.

Reproduced with permission from Narayanan U, Mulpuri K, Sankar WN, Clarke NM, Hosalker H, Price CT, Reliability of a new radiographic classification for developmental dysplasia of the hip, J Pediatr Orthop 2015;35(5):478-84, doi: 10.1097/BPO.0000000000000318. 
with a proximal tenotomy of the adductor longus.

After closed or open reduction of the femoral head, the hip is held in flexion, abduction and internal rotation. ${ }^{18}$ The degree of abduction must be maintained in the 'safe zone', as insufficient abduction predisposes to re-dislocation, and excessive abduction potentially increases the risk of osteonecrosis. ${ }^{4,12,20,26}$ The stability of hip post-reduction is assessed clinically and radiologically. If the safe zone is achievable within an arc of $20-60^{\circ}$ of abduction, a spica cast is applied prior to an MRI confirmation of concentric reduction.

\section{Open reduction}

The indications for an open reduction are failed closed reduction, a non-concentric reduction and excessive hip abduction in the spica cast. Open reductions can be performed medially or anteriorly and must manage all factors obstructing a stable concentric reduction. The patient is then immobilised in a hip spica cast prior to a transition into a hip abduction brace at the six-week mark. ${ }^{20,29,30}$
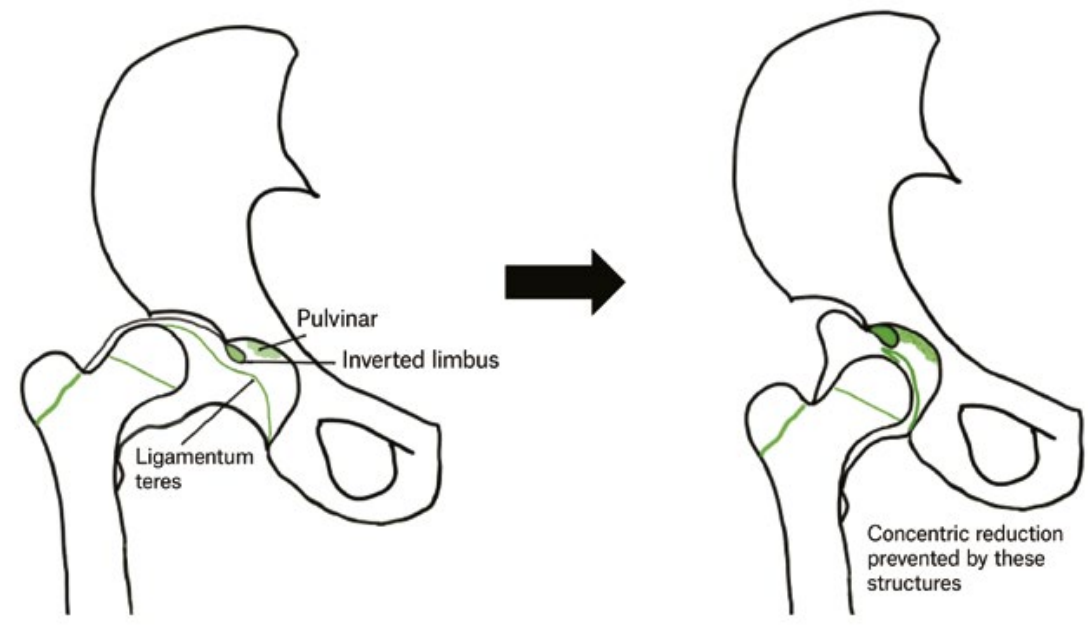

Figure 2. Intra-articular obstacles to concentric reduction of the hip in patients with developmental dysplasia of the hip
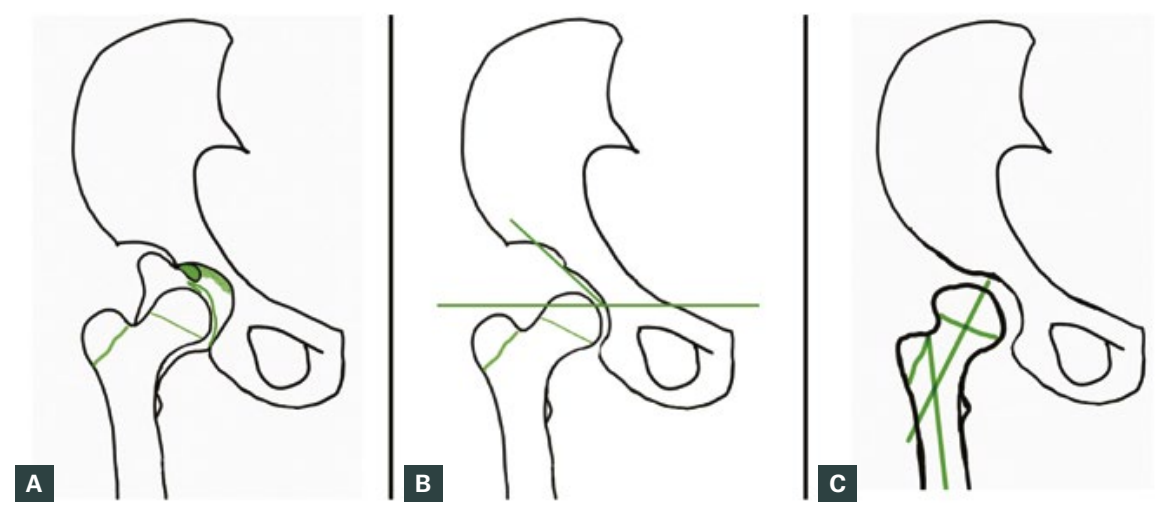

Figure 3. Potential causes of residual instability in developmental dysplasia of the hip A. Patulous and redundant capsule; B. Acetabular dysplasia; C. Proximal femoral anteversion and coxa valga

Although uncommon, re-dislocation following an open reduction is a serious complication and can markedly increase the rate of osteonecrosis. Recent modifications in technique have included transferring the ligamentum teres as a tenodesis ${ }^{20,30}$ and the development of arthroscopy-assisted techniques. ${ }^{31}$

\section{Femoral osteotomy}

The abnormal proximal femoral anatomy in DDH may predicate the need for a femoral osteotomy to achieve reduction, reduce tension and correct the joint forces around the hip. ${ }^{32-34}$ Fixation is achieved with a blade plate and can be performed to varise, de-rotate or shorten the proximal femur.

\section{Acetabular osteotomy}

Insufficient coverage of the femoral head or acetabular dysplasia may require pelvic osteotomy, especially in the late-presenting child, because of the unpredictable remodelling potential of the acetabulum. Techniques have been developed to address the problems encountered in acetabular dysplasia: an abnormally oriented acetabulum with adequate capacity or an overly capacious acetabulum resulting in a dislocatable hip. ${ }^{35-38}$

\section{Conclusion}

Recent advances in surveillance, diagnosis and management of the DDH spectrum (Table 3) have improved outcomes for many patients, but much remains to be discovered. ${ }^{25,39}$ In 2010, the IHDI initiated an international, multicentre prospective study at nine centres across Australia, North America and Europe in response to these evidence gaps in the management of infant and toddler DDH.

In the meantime, the universal tenet in $\mathrm{DDH}$ care remains that prompt diagnosis and management are the most important factors related to outcome; it is important to be cognisant about developmental hip pathology in asymptomatic patients through infancy and childhood. ${ }^{40}$

\section{Authors}

Brian Loh MBBS, BMedSci, PGradDipAnat, FRACS, FAOrthA, Orthopaedic Surgeon, Royal Children's Hospital, Melbourne, Vic 


\section{Table 3. Recent advances in the care of patients with developmental dysplasia of the hip}

\begin{tabular}{|c|c|}
\hline Pathoanatomy & $\begin{array}{l}\text { - Evolving understanding of the affected anatomy in } \mathrm{DDH} \\
\text { - Emerging knowledge about the genetic basis of DDH }\end{array}$ \\
\hline Surveillance & $\begin{array}{l}\text { - Improving sonographic techniques and better interpretation } \\
\text { of ultrasonography } \\
\text { - Increasing use of MRI for confirmation of reduction } \\
\text { - Development of International Hip Dysplasia Registry }\end{array}$ \\
\hline Management & $\begin{array}{l}\text { - Increased availability of bracing care } \\
\text { - Ligamentum tenodesis to minimise re-dislocation rate } \\
\text { - Development of arthroscopy-assisted techniques } \\
\text { - Gore-Tex and water-resistant spica cast liners }\end{array}$ \\
\hline Prevention & $\begin{array}{l}\text { - Increased awareness of safe swaddling techniques } \\
\text { - Evolution of baby carrier slings to improve infant hip } \\
\text { abduction }\end{array}$ \\
\hline
\end{tabular}

$D D H$, developmental dysplasia of the hip; MRI, magnetic resonance imaging

Emily Woollett BAppSc (ClinSc), MHSc (Osteo), Research Assistant, Loh Orthopaedics, Vic Competing interests: None.

Funding: None.

Provenance and peer review: Commissioned, externally peer reviewed.

Correspondence to:

office@brianloh.com.au

\section{References}

1. Rális Z, McKibbin B. Changes in shape of the human hip joint during its development and their relation to its stability. J Bone Joint Surg $\mathrm{Br}$ 1973;55(4):780-85

2. Graf R. Hip sonography: Diagnosis and management of infant hip dysplasia. 2nd edn. Berlin, DE: Springer-Verlag, 2006.

3. Sewell MD, Eastwood DM. Screening and treatment in developmental dysplasia of the hip - Where do we go from here? Int Orthop 2011:35(9):1359-67. doi: 10.1007/s00264-0111257-z.

4. Joseph B, Nayagam S, Loder R, Torode I. Pediatric orthopaedics: A system of decision-making. 2nd edn. Boca Raton, FL: CRC Press, 2016.

5. Australian Orthopaedic Association National Joint Replacement Registry (AOANJRR). Hip, knee \& shoulder arthroplasty: 2018 annual report. Adelaide, SA: AOA, 2018; p. 122-209.

6. Williams N. Improving early detection of developmental dysplasia of the hip through general practitioner assessment and surveillance. Aust J Gen Pract 2018;47(9):619-23. doi: 10.31128/ AJGP-03-18-4524.

7. Hatzikotoulas K, Roposch A, Shah K, et al. The genetic epidemiology of developmental dysplasia of the hip: A genome-wide association study harnessing national clinical adult data. BioRxiv 2017. doi: $10.1101 / 154013$

8. Dodinval P. [Heredity in congenital dislocation of the hip]. Acta Orthop Belg 1990;56(1 Pt A):7-11.

9. Tönnis D. Inheritance. In: Congenital dysplasia and dislocation of the hip in children and adults. Berlin, DE: Springer-Verlag, 1984; p. 61-62.
10. Carroll KL, Schiffern AN, Murray KA, et al. The occurrence of occult acetabular dysplasia in relatives of individuals with developmental dysplasia of the hip. J Pediatr Orthop 2016;36(1):96-100. doi: 10.1097/ BPO.0000000000000403.

11. Visser JD. Pediatric orthopedics: Symptoms, differential diagnosis, supplementary assessment and treatment. Cham, $\mathrm{CH}$ : Springer International Publishing, 2017.

12. Vitale MG, Skaggs DL. Developmental dysplasia of the hip from six months to four years of age. J Am Acad Orthop Surg 2001;9(6):401-11. doi: 10.5435/00124635-200111000-00005.

13. Roposch A, Stöhr KK, Dobson M. The effect of the femoral head ossification nucleus in the treatment of developmental dysplasia of the hip. A metaanalysis. J Bone Joint Surg Am 2009;91(4):911-18. doi: 10.2106/jbjs.h.00096.

14. Harcke HT, Grissom LE. Performing dynamic sonography of the infant hip. AJR Am J Roentgenol 1990;155(4):837-44. doi: 10.2214/ajr.155.4.2119119.

15. Kosar P, Ergun E, Gökharman FD, Turgut AT, Kosar U. Follow-up sonography results for Graf type 2A hips: Association with risk factors for developmental dysplasia of the hip and instability. J Ultrasound Med 2011;30(5):677-83. doi: 10.7863/ Jim.2011.30.5.677.

16. Quader N, Hodgson AJ, Mulpuri K, Schaeffer E, Abugharbieh R. Automatic evaluation of scan adequacy and dysplasia metrics in 2-D ultrasound images of the neonatal hip. Ultrasound Med Biol 2017;43(6):1252-62. doi: 10.1016/j. ultrasmedbio.2017.01.012.

17. Starr $\mathrm{V}, \mathrm{Ha} \mathrm{BY}$. Imaging update on developmental dysplasia of the hip with the role of MRI. AJR Am J Roentgenol 2014;203(6):1324-35. doi: 10.2214/ AJR.13.12449.

18. Narayanan U, Mulpuri K, Sankar WN, Clarke NM, Hosalker H, Price CT. Reliability of a new radiographic classification for developmental dysplasia of the hip. J Pediatr Orthop 2015;35(5):478-84. doi: 10.1097/ BPO.0000000000000318.
19. Ramsey PL, Lasser S, MacEwen GD. Congenital dislocation of the hip: Use of the Pavlik harness in the child during the first six months of life. J Bone Joint Surg Am 1976;58(7):1000-04.

20. Bache CE, Graham HK, Dickens DR, et al. Ligamentum teres tenodesis in medial approach open reduction for developmental dislocation of the hip. J Pediatr Orthop 2008;28(6):607-13. doi: 10.1097/bpo.0b013e318184202c.

21. Sarban S, Ozturk A, Tabur H, Isikan UE. Anteversion of the acetabulum and femoral neck in early walking age patients with developmental dysplasia of the hip. J Pediatr Orthop B 2005;14(6):410-14. doi: 10.1097/01202412200511000-00003.

22. Mladenov K, Dora C, Wicart P, Seringe R. Natural history of hips with borderline acetabular index and acetabular dysplasia in infants. J Pediatr Orthop 2002;22(5):607-12. doi: 10.1097/01241398200209000-00008.

23. Alexiev VA, Harcke HT, Kumar SJ. Residual dysplasia after successful Pavlik harness treatment: Early ultrasound predictors. J Pediatr Orthop 2006;26(1):16-23. doi: 10.1097/01. bpo.0000187995.02140.c7.

24. Upasani VV, Bomar JD, Matheney TH, et al. Evaluation of brace treatment for infant hip dislocation in a prospective cohort: Defining the success rate and variables associated with failure. J Bone Joint Surg Am 2016;98(14):1215-21. doi: 10.2106/JBJS.15.01018.

25. Aarvold A, Schaeffer EK, Kelley S, et al. Management of irreducible hip dislocations in infants with developmental dysplasia of the hip diagnosed below 6 months of age. J Pediatr Orthop 2019;39(1):e39-e43. doi: 10.1097/ BPO.0000000000001205.

26. Gardner RO, Bradley CS, Howard A Narayanan UG, Wedge JH, Kelley SP. The incidence of avascular necrosis and the radiographic outcome following medial open reduction in children with developmental dysplasia of the hip: A systematic review. Bone Joint J 2014;96-B(2):279-86. doi: 10.1302/0301620X.96B2.32361.

27. Wilkinson AG, Sherlock DA, Murray GD. The efficacy of the Pavlik harness, the Craig splint and the von Rosen splint in the management of neonatal dysplasia of the hip. A comparative study. J Bone Joint Surg Br 2002;84(5):716-19. doi: 10.1302/0301-620x.84b5.12571.

28. Malvitz TA, Weinstein SL. Closed reduction for congenital dysplasia of the hip. Functional and radiographic results after an average of thirty years. J Bone Joint Surg Am 1994;76(12):1777-92. doi: 10.2106/00004623-199412000-00004.

29. Holman J, Carroll KL, Murray KA, Macleod LM, Roach JW. Long-term follow-up of open reduction surgery for developmental dislocation of the hip. J Pediatr Orthop 2012;32(2):121-24. doi: 10.1097/ BPO.0b013e3182471aad.

30. Wenger DR, Mubarak SJ, Henderson PC, Miyanji F. Ligamentum teres maintenance and transfer as a stabilizer in open reduction for pediatric hip dislocation: Surgical technique and early clinical results. J Child Orthop 2008;2(3):117-85. doi: 10.1007/s11832-008-0103-3.

31. Eberhardt O, Wirth T, Fernandez FF. Arthroscopic reduction and acetabuloplasty for the treatment of dislocated hips in children of walking age: A preliminary report. Arch Orthop Trauma Surg 2014;134(11):1587-94. doi: 10.1007/s00402-0142063-z.

32. Wenger DR, Lee CS, Kolman B. Derotational femoral shortening for developmental dislocation of the hip: Special indications and results in the 
child younger than 2 years. J Pediatr Orthop 1995; 15(6):768-79. doi: 10.1097/01241398-19951100000009.

33. Ryan MG, Johnson LO, Quanbeck DS, Minkowitz B. One-stage treatment of congenital dislocation of the hip in children three to ten years old. Functional and radiographic results. J Bone Joint Surg Am 1998;80(3):336-44. doi: 10.2106/00004623-199803000-00005

34. Spence G, Hocking R, Wedge JH, Roposch A. Effect of innominate and femoral varus derotation osteotomy on acetabular development in developmental dysplasia of the hip. J Bone Joint Surg Am 2009;91(11):2622-36. doi: 10.2106/ jbjs.h.01392.

35. Gillingham BL, Sanchez AA, Wenger DR. Pelvic osteotomies for the treatment of hip dysplasia in children and young adults. J Am Acad Orthop Surg 1999;7(5):325-37. doi: 10.5435/00124635199909000-00005.

36. Kitoh $\mathrm{H}$, Kaneko H, Ishiguro N. Radiographic analysis of movements of the acetabulum and the femoral head after Salter innominate osteotomy. J Paediatric Orthop 2009;29(8):879-84. doi: 10.1097/bpo.0b013e3181c1e314.

37. DelBello DA, Nattrass GR, Moseley CF, Watts $H G$. Acetabular development after open reduction in developmental dysplasia of the hip: The role of concurrent innominate osteotomy. Orthop Trans 1995;19:298.

38. Albinana J, Dolan LA, Spratt KF, Morcuende J, Meyer MD, Weinstein SL. Acetabular dysplasia after treatment for developmental dysplasia of the hip. Implications for secondary procedures. J Bone Joint Surg Br 2004;86(6):876-86. doi: 10.1302/0301-620x.86b6.14441.

39. Yamamuro $T$, Ishida K. Recent advances in the prevention, early diagnosis and treatment of congenital dislocation of the hip in Japan. Clin Orthop Relat Res 1984;(184):34-40. doi: 10.1097/00003086-198404000-00005.

40. Rosenberg N, Bialik V, Norman D, Blazer S. The importance of combined clinical and sonographic examination of instability of the neonatal hip. Int Orthop 1998;22(3):185-88. doi: 10.1007/ s002640050238. 